\title{
Nos 50 anos da ECA-USP, a Educomunicação alcança maturidade acadêmica e legitimidade política
}

Ismar de Oliveira Soares

Presidente da Associação Brasileira de Pesquisadores e Profissionais da Educomunicação (www. abpeducom.org.br).

E-mail: ismarolive@yahoo.com

Enumerar estes acontecimentos permite ao leitor elaborar sua própria imagem a respeito da natureza do movimento que mobilizou, nas últimas décadas - com a visível contribuição do Departamento de Comunicações e Artes da ECA-USP e do Núcleo de Comunicação e Educação - diferentes gerações de agentes sociais, em todo o país, em torno de uma práxis que tem sido capaz de realizar uma costura intergeracional a partir da utopia da transversalidade das relações de comunicação nas práticas educativas.

Referimo-nos a um conjunto de eventos que se sucederam, entre os quais:

\section{COLÓQUIOS E CICLOS DE ESTUDO}

- O II Colóquio Mato-Grossense de Educomunicação e I Seminário Virtual de Práticas Educomunicativas, em Alto do Araguaia, MT, de 13 a 18 de junho;

- O Colóquio Ibero-Americano e Catarinense de Educomunicação e VI Colóquio Catarinense de Educomunicação, em Florianópolis, SC, de 1 a 2 de setembro;

- O Ciclo da Intercom, no XXXIX Congresso da entidade sobre "Comunicação e educação: caminhos integrados para um mundo em transformação", São Paulo, SP, de 5 a 6 de setembro, com o tema "Comunicação e Educação, Caminhos Cruzados";

- O GP em Comunicação e Educação do XXXIX Congresso da Intercom (São Paulo, 7 e 8 de setembro), com o tema educomunicação presente em $50 \%$ dos papers apresentados.

- Reunião de especialistas em educação midiática do Chile e do Brasil, no dia 27 de outubro, no campus da Universidad Mayor de Chile, na cidade de Santiago, para discutir processos de articulação de políticas públicas de educação midiática e de educomunicação nos dois países. 


\section{PROJETO INOVADOR}

- Projeto Geraçãocidadã.2016, unindo, numa perspectiva interistitucional, professores e dois grupos de alunos vinculados ao Colégio Dante Alighieri, da rede particular de ensino de São Paulo, e à CEU-EMEF Casa Blanca, da Diretoria de Educação de Campo Limpo, da SME-SP, com a promoção de atividades educomunicativas colaborativas, envolvendo adolescentes, assistidos pelo NCE-USP e pela ABPEducom - Associação Brasileira de Pesquisadores e Profissionais da Educomunicação, com a utilização de um estúdio móvel de audiovisual, instalado num antigo ônibus escolar do Dante. O projeto se desenvolveu ao longo de todo o ano de 2016, tendo sido concluído no dia 29 de outubro e apresentado por seus protagonistas (os adolescentes) no VII Educom (3 de novembro) e no espaço do Senado Federal (7 de novembro).

\section{SEMINÁRIOS}

- O Seminário sobre Educomunicação e práxis social: perspectivas epistemológicas em debate na Europa e no Brasil (São Paulo, SP, 20 a 31 de agosto), no contexto dos 50 anos da ECA-USP e dos 20 anos do NCE-USP, com a presença do professor visitante José Ignacio Aguaded Gómez, diretor da revista Comunicar, de Huelva, Espanha.

- O VII Encontro Brasileiro de Educomunicação, da ABPEducom, com o tema: "Mídia e alfabetização midiática: novos paradigmas para o diálogo intercultural" (São Paulo, 3 a 5 de novembro), no contexto do V Global MIL Week, da Unesco.

- O Seminário do Conselho de Comunicação Social do Congresso Nacional sobre "Educação midiática e informacionalno Brasil - um olhar a partir da perspectiva da Unesco”, ocorrido em Brasília, no dia 7 de novembro.

No conjunto desses eventos foram apresentados 260 trabalhos em 80 painéis, com a participação direta de aproximadamente 2 mil interessados.

\section{EDUCOMUNICAÇÃO DE SANTIAGO A SÃO PAULO}

Chamou a atenção a natureza de alguns desses eventos, especialmente os ocorridos entre outubro e novembro de 2016, mobilizando especialistas, crianças e jovens, em cidades como Santiago, São Paulo e Brasília.

A reunião de 27 de outubro, no campus da Universidad Mayor, aproximou pesquisadores e promotores de práticas na interface Comunicação/Educação do Chile e do Brasil, visando um mútuo conhecimento. Dentre os participantes encontrava-se Valério Fuenzalida, conhecido promotor da educação midiática, na década de 1980, e voltado, atualmente, para os estudos de recepção, bem como para as relações entre a infância e a televisão. O diálogo que se estabeleceu foi marcado pela rememoração dos encontros sobre "Educação para a Televisão", ocorridos entre 1985 e 1991, respectivamente, em Santiago, Curitiba, Buenos 
Aires e Las Vertientes, no Chile, com o apoio da Unesco, momento em que se promoveu uma primeira sistematização do pensamento latino-americano sobre metodologias dialéticas de educação para a comunicação. Recordou-se, na ocasião, que o livro que sumarizou os resultados dos quatro encontros (Educación para la Comunicación, Manual Latino-americano), editado por Ceneca (Santiago, 1992), ofereceu importantes referenciais para a consolidação do pensamento educomunicativo na ECA-USP no final dos anos de 1990.

O encontro da Universidad Mayor de Chile representou um passo significativo na reaproximação entre estudiosos latino-americanos do campo da educação midiática. Outro passo viria a ocorrer nove dias depois, em São Paulo, no dia 5 de novembro, na reunião promovida pela ABPEducom, no campus da ECA-USP, com 95 especialistas do Brasil, Cuba, Equador, Argentina, Colômbia e México, tendo como meta o desenho de um programa de mobilização pela educomunicação na América Latina.

Na sequência ao evento do Chile, ocorreu, na ECA-USP, entre 3 e 5 de novembro, o V Global MIL Week (Semana Global sobre Media and Information Literacy), numa promoção da Unesco. Integrando a semana, a ABPEducom e o NCE-USP promoveram o VII Encontro Brasileiro de Educomunicação, com 36 painéis, por onde circulou um total de 400 inscritos interessados em conhecer as contribuições de 136 autores de artigos sobre o tema do evento: "Mídia e alfabetização midiática: novos paradigmas para o diálogo intercultural".

O Painel 1 do VII Educom, com duração de cinco horas, foi constituído pela apresentação, por seus próprios protagonistas, de uma série de práticas educomunicativas envolvendo crianças de 6 a 9 anos (Rádio Cartola, da SME-SP); adolescentes de 10 a 14 (Projeto Educom.geraçãocidadã.2016, interinstitucional, unindo escola privada e pública); jovens de 15 a 17 (Projeto Idade Mídia, do Colégio Bandeirantes e Imprensa Jovem, da SME-SP); além de jovens-adultos de 18 a 25 anos (Revista Viração e Projeto Rede Nacional de Adolescentes e Jovens Comunicadores).

Na sessão de encerramento do Global MIL Week, a canadense Carolyn Wilson, em diálogo com o presidente da ABPEducom, presente à mesa, rememorou sua vinda ao Brasil, em 1989, quando era uma jovem professora, tendo participado ativamente do International Congress on Communication and Education, promovido pelo NCE-USP, em São Paulo. Em sua fala, Carolyn garantiu que foi visivelmente impactada pelo pensamento brasileiro em torno da relação comunicação/educação. Por seu lado, Alton Grizzle, da Unesco, confessou publicamente que ficou impressionado com a vitalidade do conceito da educomunicação e com a presença das crianças e jovens no evento global.

Uma das últimas intervenções da sessão de encerramento do evento internacional coube a um dos adolescentes da Imprensa Jovem, integrado à cobertura educomunicativa do evento, que pediu mais espaço para as crianças em futuros encontros sobre o tema da educação midiática: "As crianças e os jovens têm muito o que dizer", afirmou ele. 
Ganhou, igualmente, destaque a presença, em frente ao prédio central da ECA, do estúdio móvel do projeto Dante em Foco, com adolescentes do Colégio Dante Alighieri realizando entrevistas com especialistas internacionais, em inglês e espanhol.

\section{BRASÍLIA: A LEGITIMAÇÃO DA EDUCAÇÃO NO ESPAÇO DO CCS}

A TV Senado transmitiu para todo o país, na manhã do dia 7 de novembro em Brasília, as atividades do seminário promovido pelo Conselho de Comunicação Social do Congresso Nacional, com o título: "Educação midiática e informacional no Brasil - um olhar a partir da perspectiva da Unesco".

Coordenado pelo presidente da ABPEducom, o seminário contou com as presenças das professoras Raquel Paiva, pesquisadora do Laboratório de Estudos em Comunicação Comunitária da UFRJ, e Sandra Zita Silva Tine, assessora técnica da Coordenação Geral do Ensino Fundamental, Diretoria de Currículos e Educação Integral, da Secretaria de Educação Básica do MEC. Pela Unesco, falou Alton Grizzle - diretor de Desenvolvimento da Mídia e da Liberdade de Expressão e Coordenador do Programa GAPMIL (Global Alliance for Partnership on Media and Information Literacy).

A grande novidade da mesa foi contar com a intervenção das adolescentes Clarice Villari (aluna do Colégio Dante Alighieri de São Paulo); e Maria Eduarda Silva de Oliveira (aluna do CEU-EMEF Casa Blanca de São Paulo), que apresentaram o projeto Educom.geraçãocidadão.2016, que uniu o Colégio Dante Alighieri e a EMEF Casa Blanca, numa proposta educomunicativa interinstitucional, assistida pela ABPEducom e pelo NCE-USP. Na plateia, junto com os membros do Conselho (representantes da grande mídia, trabalhadores do setor das comunicações e representantes da sociedade civil), estavam as adolescentes Júlia Assis Azevedo e Maria Beatriz do Nascimento Manuel, vinculadas ao mesmo projeto, assim como as professoras que as acompanhavam: Verônica Martins Cannetá e Lucilene Varandas.

Todos os cinco integrantes do painel - incluindo o representante da Unesco - referiram-se à educomunicação como um caminho para as políticas públicas de educação no Brasil.

Sandra Zita Tiné, da Diretoria de Currículos e Educação Integral da Secretaria de Educação Básica do MEC, abordou, em sua exposição, a experiência do projeto Mais Educação, do MEC, que atende, no momento, a 4 milhões de meio de alunos, que se expressam por meio de jornais e rádios escolares, em atividades inerentes ao universo da "Comunicação, Mídias e Tecnologias da Informação".

Raquel Paiva, professora da UFRJ, destacou a importância de habilitar os cidadãos de todas idades, gêneros e qualquer nível de instrução a ler, a interpretar as produções midiáticas: 
A relação entre educação e comunicação está dada desde o início de todas as discussões em torno do consumo das produções midiáticas. O que eu valoro como ponto fulcral na atuação da proposta da Educomunicação é o fato de ela ter se transformado numa presença concreta, em inúmeras escolas, há praticamente duas décadas, principalmente pelo fato de aliar ao questionamento crítico o aspecto da produção. Quando a escola insere a produção, ela entra na seara do lúdico, e é essa, talvez, a única esfera capaz de fazer frente a esse do universo dominado pelo sensório.

Alton Grizzle viu pontos de contato entre a proposta da Unesco e as práticas defendidas pelos educomunicadores na América Latina. Afirmou ele:

A Unesco usa a expressão 'informação e alfabetização midiática', que é muito similar ao que estamos chamando de Educomunicação, no Brasil. O trabalho da Unesco sobre essa informação midiática se concentra em fortalecer o uso livre e democrático da mídia, em promover a capacitação para o jornalismo profissional e para os especialistas de informação em mídia e infraestrutura. Nós também olhamos o marco regulatório e propomos metodologias para implementar a educação midiática e informacional como política pública em todo o mundo.

O seminário de Brasília representou, sem qualquer sombra de dúvida, a legitimação da Educomunicação com projeto político-pedagógico a ser implantado mediante políticas públicas, em todo o país.

\section{ARTIGOS NACIONAIS}

Esta edição traz algumas experiências educomunicativas presentes em diversos contextos e regiões do Brasil.

Guilherme Carvalho, Toni André Scharlau e Evanise Rodrigues Gomes apresentam em "De Curitiba para Moçambique", o Núcleo de Comunicação e Educação Popular, um programa de extensão universitária criado em 2003, junto ao Departamento de Comunicação da Universidade Federal do Paraná (Decom-UFPR), com o objetivo de estimular a discussão sobre educomunicação e comunicação popular. No artigo, os autores trazem resultados alcançados pela equipe, além de fornecer breves relatos das experiências, como as oficinas de redação e produção em rádio e em jornal impresso, e uma parceria internacional com a Universidade Eduardo Mondlane, de Moçambique, relatada em destaque.

Em "Rap da Roça", Pablo Nabarrete Bastos apresenta resultados de sua pesquisa sobre a formação política do Movimento dos Trabalhadores Rurais Sem Terra (MST), em que mostram que as narrativas dos jovens camponeses sinalizam aproximação política entre a juventude desses espaços por meio da identificação cultural, o que pode fortalecer e aprofundar as alianças e os diálogos políticos.

Patrícia Nápolis, Alessandro Façanha e Jociara Pinheiro Luz revelam em seu artigo, "Educomunicação científica", as conexões entre a rádio universitária e o processo de educomunicação científica. Katia Zanvettor Ferreira faz uma reflexão acerca das intersecções entre o professor e o jornalismo, trazendo uma 
reconstrução das imagens do professor que predominam nas publicações dos jornais, no artigo "O jornalismo e professores".

Em "O que é autor de telenovela", Marines Boncoski Brizola e Marlene Gonçalves Mattes apresentam os conceitos de autor, autoria, coautoria, texto-obra-criação, bem como de escrita colaborativa e de telespectador-modelo, no que se refere às telenovelas produzidas no Brasil.

\section{ARTIGO INTERNACIONAL}

Valerio Fuenzalida, professor e pesquisador da área de audiovisual da Pontifícia Universidade Católica do Chile, é especialista em TV pública e infantil, além de linguagem e gêneros televisivos. No artigo, ele trata do surgimento de uma nova representação televisiva do público infantil e para um construtivismo cultural na recepção. Segundo ele, os novos programas representam uma criança com competências socioemocionais, e esta nova representação infantil, mais complexa, convoca uma audiência construtivista dos programas.

\section{EXPERIÊNCIA}

O artigo "Educação e Mediação Escolar", de Ana Lucia Penteado Brandão Prado, é baseado em monografia para obtenção do título de especialista em Educomunicação cuja defesa ocorreu em 2015, orientada pela professora doutora Maria Cristina Palma Mungioli, e aborda a relação entre infância e consumo a partir de seu estímulo pelas mídias contemporâneas.

\section{ENTREVISTA}

O professor catedrático da Universidade de Huelva (Espanha), Ignacio Aguaded, é o entrevistado desta edição. Ele destaca o papel da Educomunicação e da educação midiática, e também comenta as políticas que estão sendo debatidas e implantadas na Europa. Aguaded é também diretor do Grupo Comunicar, cuja publicação é, hoje, pela alta qualidade científica que apresenta, um dos principais canais para a reflexão crítica entre pesquisadores das áreas de Comunicação e Educação.

\section{CRÍTICA}

Celso Frederico parte da análise da peça teatral "Filha moça" para começar a reflexão crítica do artigo. A peça, escrita em 1956 pelo dramaturgo Augusto Boal, para ser montada pelo Teatro Experimental do Negro, foi totalmente censurada antes mesmo de ser encenada, a exemplo de vários espetáculos da época. Para o autor, essa peça dificilmente seria censurada hoje, pois a censura 
da atualidade aparece de outras maneiras mais sutis, mas nem por isso menos eficazes.

\section{DEPOIMENTO}

Seção destinada a recolher histórias de vida, experiências, percursos de trabalho em comunicação e educação, traz, sob o título de "A trajetória da criação das atividades para sala de aula, na perspectiva da construção da Educomunicação", o depoimento de Ruth Ribas Itacarambi, pesquisadora aposentada do IME-USP. Desde os anos 2000, a professora é colaboradora da revista Comunicação Ẽ Educação, com a coluna "Atividades em Sala de Aula". Nesse depoimento, ela nos relata, além de sua história de vida, os desafios enfrentados a cada edição da revista.

\section{POESIA}

O professor Arlindo Rebechi Junior preparou um texto para falar do poeta italiano Pier Paolo Pasolini, em suas diversas fases de produção. Segundo ele, a crítica cultural de Pasolini, levou um ensaísmo de forte penetração aos meios intelectuais "realizando incursões pelo cinema, pela literatura e pela cultura e política de sua época, tendo a coragem de apontar, sem meias palavras, os dilemas e assimetrias trazidos pela nova sociedade capitalista do século XX, forjada no consumo e nos tempos de comunicação de massa”.

\section{RESENHAS}

Maria Ignês Carlos Magno e Celia Cristina Torres sugerem os filmes $A$ Negra de... e Moolaadè!, do cineasta senegalês Osmane Sembène, no sentido de propor o conhecimento do cinema africano. Andréa Antonacci resenha o livro de Marcia Tondato e Maria Aparecida Baccega, A telenovela nas relações de comunicação e consumo: diálogo Brasil e Portugal, publicado pela Paco Editorial, sobre as relações entre comunicação e consumo na telenovela. Tissiana Pereira apresenta, em sua resenha, um apanhado dos principais dados abordados no Anuário Obitel 2016 - (Re) Invenção de Gêneros e Formatos da Ficção Televisiva, coordenado por Maria Immacolata Vassallo de Lopes e Guilhermo Orozco Gómez.

\section{ATIVIDADES EM SALA DE AULA}

Ruth Ribas Itacarambi propõe atividades de trabalho para serem realizadas em sala de aula com alunos do ensino fundamental e médio, a partir de artigos publicados neste número da nossa revista. 